\title{
Movimientos sociales, redes sociales y recursos simbólicos
}

Recibido: 18 de agosto de 2015

Aceptado: 23 de marzo de 2016

Publicado: 30 de noviembre de 2016
Amaro La Rosa

amaro@unife.edu.pe

Universidad Femenina del Sagrado Corazón (Perú)

Resumen: El artículo presenta una visión actualizada del papel que desempeñan las redes sociales en los movimientos sociales contemporáneos. Se realiza una somera revisión de la teoría de los movimientos sociales y sus implicancias, enfatizando en su vinculación con procesos de comunicación y narrativas específicas. Finaliza con el recuento de algunos recursos simbólicos empleados por movimientos sociales en diversas realidades.

Palabras clave: Movimientos sociales, redes sociales, interacción, narrativas.

Abstract: The paper presents an updated approach of the social media role in the contemporary social movements. Drawing from the explanation of some viewpoints about interaction in the social media, a brief review about social movements theory and their implications is presented, emphasizing in their relationship with communication processes and specific storytellings.. Finally, some symbolic resources used by social movements in diverse realities are described.

Key words: Social Movements, Social Media, Interaction, Storytelling.

\section{Introducción}

En términos generales, a nuestro entender, a lo largo de la historia de la humanidad ha existido siempre una interconexión muy estrecha entre comunicación, tecnología y sociedad. Los vestigios encontrados nos permiten comprender que casi desde los albores de la sociedad humana, con la finalidad de resolver problemas diversos, se desarrolló la 
tecnología y se usaban recursos de comunicación para trasmitir mensajes o para dejar constancia de la realidad observada. Así, hace unos 30 mil años los "primitivos" seres humanos del paleolítico pintaban en las cuevas de Lascaux, simbolizando parte de la bóveda celeste, tal como lo demostraron los estudios de Chantal Jègues-Wolkiewiez (2012).

Los movimientos sociales han apelado siempre a modalidades diversas de comunicación, ya sea para difundir sus ideas a sus potenciales seguidores e influenciar a la sociedad en pro de la acción colectiva o para intentar imponerlas de manera coercitiva en un ámbito determinado. Durante largo tiempo, los volantes fueron los recursos de comunicación y difusión más utilizados por los movimientos sociales. Elaborados con presupuesto reducido en papeles de baja calidad, requerían limitada experiencia para producirse, se contaba con tecnología asequible para producirlos, eran fáciles de almacenarse, de ocultarse (en caso necesario) y de distribuirse a públicos masivos con limitado riesgo, aun cuando en algunos casos fueron detectados, tal como sucedió con los integrantes del grupo de resistencia alemán "Die weiße Rose", quienes fueron ejecutados luego de distribuir volantes en la Universidad de Munich.

Posteriormente, los carteles llegaron a ser verdaderas obras de arte muy motivadoras, cuya historia y las de sus creadores merecerían decenas de libros. Para Protzel (2016), los carteles muestran un maridaje entre composición gráfica y propaganda política. Al respecto, durante el movimiento de Mayo del 68, cientos de carteles aparecieron en Francia (especialmente en París) promoviendo la participación en las movilizaciones. Los avances de la tecnología no se detuvieron y durante las protestas de 1989 en China, faxes y grabaciones en videocasetes se usaron para motivar la ocupación de la Plaza Tiananmén (Beijing), que semanas más tarde culminara en una masacre cuando el gobierno chino ordenó que las tropas desalojaran el lugar.

En agosto y septiembre de 2007, en las calles de varias ciudades de la antigua Birmania (rebautizada como Myanmar) miles de monjes budistas, en contraposición con su habitual postura pacífica y de meditación, protestaron por varios días en las calles contra la dictadura y el aumento en los precios de la gasolina y el gas, utilizando sus teléfonos móviles y transmitiendo mensajes de texto motivando a los ciudadanos para participar activamente en las movilizaciones, enviando fotos y videos que mostraban la violenta represión.

En las conclusiones de un estado del arte sobre los movimientos sociales publicado hace tres lustros, en el cual se vislumbran los indicios de lo que hoy sucede, Ibarra (2000: 285) asume que los movimientos sociales "han ampliado sus capacidades de movilización. Posibilidades que Internet les facilita. Por ejemplo, logran un creciente impacto que incrementa sensiblemente su potencial movilizador". Como hemos podido comprobar a través de los años, en consonancia con el desarrollo tecnológico de la Internet, este potencial se ha incrementado considerablemente y es evidente que ha trascendido los alcances que podían suponerse. Con el advenimiento de la web 2.0 y la evolución de las redes sociales, los movimientos sociales pudieron contar con nuevos y variados recursos.

En los últimos años, un sinnúmero de movimientos sociales producidos en diversas partes del mundo han utilizado a los medios sociales como plataformas de difusión, motivación, y acción social. La intensidad así como el impacto social que determinaron no ha sido siempre 
de la misma trascendencia. Sin embargo, son muy ilustrativos en cuanto al poder de los medios sociales como recursos para fortalecer a la ciudadanía y fortalecer la democracia.

Twitter cambió considerablemente el accionar de las protestas. En contra de quienes dudaban inicialmente sobre su real trascendencia, el sitio de microblogging desde hace años constituye un instrumento muy importante, con una evidente participación en los grandes movimientos sociales así como en la vida política alrededor del mundo, la cual muchas veces resulta impactada con un solo tuit, escrito por algún líder de opinión, que se convierta luego en tema de la agenda mediática. Las cadenas de difusión y motivación generadas por los mensajes, fotos o videos publicados en Facebook (así como los videos alojados en YouTube o las fotografías en Flickr), han desempeñado desde luego un rol de marcada importancia, tal como se ha comprobado fehacientemente en diversos casos como el de la denominada "Primavera árabe".

El desarrollo de los teléfonos móviles inteligentes, la disminución de sus costos, la digitalización de las comunicaciones y el creciente acceso a la banda ancha, han contribuido a que estos recursos estén ahora al alcance de sectores cada vez más amplios de la comunidad, que pueden así contar con un recurso tecnológico tanto para difundir los hechos (de los cuales son testigos privilegiados) como para tomar parte activa en iniciativas ciudadanas.

En esta época, las redes sociales constituyen recursos muy importantes para los movimientos sociales, los cuales pueden surgir y crecer tan pronto como lo permita la tecnología y el acceso a la misma. En ciertos casos, el mismo día en el cual se recibe el primer impulso motivacional por parte de individuos, actores sociales u organizaciones. La implementación de prácticas gubernamentales restrictivas, por lo general, se hace efectiva muy tarde, cuando los mensajes ya están circulando raudamente por el ciberespacio y los han visto o leído miles de personas en las pantallas de sus computadoras, teléfonos móviles o tablets.

Irán, Birmania y China, entre otros países, han aplicado (en su momento) severas restricciones para el uso de la Internet y las redes sociales. Pese a ello, la ciudadanía siguió haciendo un uso creativo de las redes, buscando atajos y nuevas formas de colaboración para manifestar su criterio y motivar que más personas se involucren en las acciones de protesta. Seguramente algunos sitios o cuentas pudieron ser hackeadas, desactivadas o bloqueadas, pero las huellas profundas dejadas por los mensajes de los activistas de movimientos sociales ya se habían difundido y permanecen aún activas para su conocimiento, difusión e investigación en innumerables lugares en el ciberespacio.

\section{Apuntes sobre los movimientos sociales}

Concordando con el punto de vista de Della Porta y Diani (2006), entendemos que los movimientos sociales suponen cuatro elementos:

- Interacción informal: modalidades de relación interpersonal desarrolladas, sin contar con una base de reglas preestablecidas de intercambio. 
- Creencias compartidas: al menos algunos criterios sobre los cuales existe el mayor grado de consenso posible, compartido por quienes integran el colectivo, no mensurable en términos de número de integrantes.

- Compromiso en la acción colectiva: acuerdo tácito de comprometerse en conjunto para actuar frente a determinada situación. Esto no implica necesariamente que esta actuación se produzca de la misma manera o con la misma intensidad.

- Protesta: reacciones que involucran comportamientos colectivos públicos de diverso orden, desde marchas pacíficas hasta movilizaciones en diversos lugares y ocupación de espacios públicos.

En concordancia con este criterio, luego de la revisión de varios autores, hemos encontrado una serie de definiciones de movimientos sociales que, en términos generales, poseen rasgos comunes, los cuales integramos y comparamos en un mapa mental (figura 1).

Figura 1: Concordancias en conceptos de movimientos sociales.

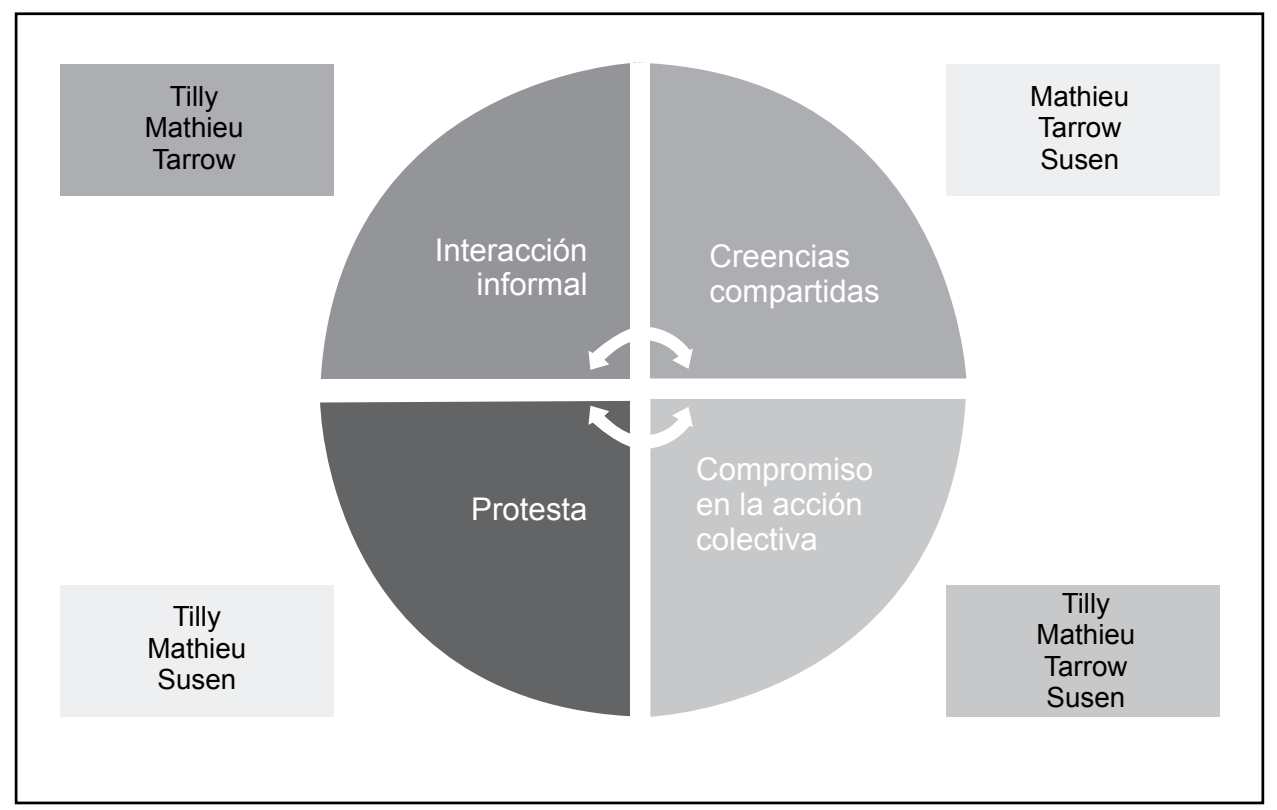

Fuente: Elaboración propia, basada en Della Porta y Diani (2006), Tilly (2004: 7), Mathieu (2004), Tarrow (2012: 37) y Susen (2010).

Nos parece pertinente agregar en este particular que los movimientos sociales no se producen en modo alguno por generación espontánea y que si bien utilizan los recursos digitales no dependen exclusivamente de ellos. De modo simplificado, a nuestro entender, estimamos que son necesarios una serie de factores que intervienen en su desarrollo: 
- Una situación social previa: condiciones de diverso orden que se evidencian al interior de la sociedad y que predisponen al surgimiento y expansión de los movimientos sociales.

- Una situación coyuntural: una problemática específica que surge en un momento determinado en la sociedad y que desencadena las acciones.

- Actores sociales comprometidos: individuos decididos a participar activamente en las acciones de protesta ya sea como líderes, motivadores o seguidores.

- Acceso a redes sociales: posibilidad de contactarse a través de redes sociales, de manera creciente utilizando teléfonos móviles inteligentes.

Desde una perspectiva estructuralista, los movimientos sociales no pueden entenderse como la sumatoria de acciones individuales. Compartiendo los términos de Taştan (2013: 26), "están integrados por diversos componentes los cuales configuran una entidad colectiva". Del mismo modo, hemos observado algunos contrastes que ameritan describirse someramente. Silva (2010) reporta el contraste en torno a las metas usuales de los movimientos sociales. En el pasado, promovían un cambio en la sociedad en su conjunto. En la actualidad, su interés está generalmente fragmentado y lo que intentan es la solución de problemas particulares de algunos sectores sociales. Al respecto, el estudio de Conover, Ferrara, Menczer y Flammini (2013) aprecia que en el "movimiento Occupy" se motivó la participación desde un conjunto de usuarios de Twitter altamente interconectados, con intereses preexistentes en la política doméstica y los movimientos sociales foráneos.

Otro contraste que encontramos revisando la literatura especializada. Según el criterio de Maxwell, Oliver y Prahl (1988), un rasgo básico era que los participantes en movimientos sociales de antaño provinieran de relaciones interpersonales preexistentes. En cambio, en la era de las redes sociales, las relaciones se configuran en gran parte en función del activismo funcional, que se expresa a través de los contactos online que se van haciendo efectivas vía las redes sociales que van motivando la participación en acciones determinadas y cuyo propio curso de acción se puede ir reorientando con rapidez por la propia naturaleza interactiva de los sistemas de comunicación empleados. Así, por ejemplo, en función de las condiciones de la coyuntura, pueden variarse las rutas de movilización, los lugares de encuentro o las horas de inicio de determinadas acciones.

\section{Movimientos sociales, redes sociales y comunicación}

Encontramos que en los movimientos sociales se registra una conexión consistente entre comunicación y acción. Centramos nuestro planteamiento en las redes sociales, basándonos en la revisión y análisis de la evidencia científica más reciente. Coincidiendo con una serie de estudios sobre los movimientos sociales, Conover, Davis, Ferrara, McKelvey, Menczer y Flammini (2013: 1) estiman que son dos los elementos clave en los cuales deben centrarse los movimientos sociales para lograr sus fines: 
- Movilización de recursos: cómo adquirir y manejar los recursos materiales, económicos y humanos que se requieren para hacer sostenible las operaciones.

- Enfoque colectivo: involucra la construcción de narrativas e imaginarios que recojan lo sustancial de la protesta para posicionarla apropiadamente.

Anuestro entender, el primero tiene que ver con la logística y la propia supervivencia del sistema que configura el movimiento social, mientras que el segundo involucra el componente creativo que motivará la adhesión, promoción, difusión y movilización de los seguidores. En este en particular, la interacción conlleva el uso de recursos simbólicos para compartir ideas, difundir criterios o informar sobre el futuro deseado del movimiento. Desde luego, esto no quiere decir que estos significados estén al margen de lo social, pues a decir de Villafuerte (2007: 177) los movimientos sociales involucran “una recreación y resignificación de los universos simbólicos de la sociedad".

Una característica fundamental de la web 2.0 es la interactividad y esto resulta de suma utilidad para los movimientos sociales, dado su interés que sus activistas cuenten con mayores recursos de fácil acceso y que cualquier usuario de la red (sea o no integrante del movimiento) pueda aportar con recursos de información. La ventaja para decirlo, en términos de Iosifidis, Tsapanos y Pitas (2016: 2) es que las redes sociales "proporcionan difusión de la información de doble vía que permite al usuario compartir su información con otros usuarios, acceder a su información y comunicarse con ellos".

Asumimos que las redes sociales están relacionadas con los dos elementos clave para los movimientos sociales pues, tal como lo demuestra la evidencia de casos sucedidos en los últimos años, han facilitado tanto la coordinación entre los integrantes como la propia comunicación. Martínez Romero (2012) plantea tres dimensiones de los movimientos sociales: a) estructura de oportunidad política, b) marcos para la acción colectiva y c) estructura de movilización. En cada una de ellas, la comunicación tiene una función específica (figura 2).

Figura 2: Dimensiones de los movimientos sociales.

\begin{tabular}{|l|l|}
\hline \multicolumn{1}{|c|}{ DIMENSIÓN } & \multicolumn{1}{|c|}{ FUNCIÓN DE LA COMUNICACIÓN } \\
\hline Estructura de oportunidad política & $\begin{array}{l}\text { Identificar aliados > Mostrar puntos vulnerables del Estado > Crear } \\
\text { oportunidades para seguidores }\end{array}$ \\
\hline Marcos para la acción colectiva & Difusión del mensaje para la creación y movilización del consenso \\
\hline Estructura de movilización & Uso de TIC - Fortalecimiento de la estructura organizativa del movimiento \\
\hline
\end{tabular}

Fuente: Elaboración propia, basado en Martínez (2012: 37). 
Desde el punto de vista de Candón (2011) la sociedad en red facilita la puesta en escena de actores sociales quienes no responden necesariamente a los estilos de vida y de comportamiento de los actores políticos tradicionales. Cuando surge una demanda social, ellos pueden difundirla a muchas personas en un plazo muy breve usando redes sociales, cadenas de correo o mensajes de texto, lo cual sería materialmente imposible con una interacción directa, cara a cara. Realizando un ejercicio especulativo quien sabe si estos actores lograrían un impacto similar en situaciones de interacción offline.

El estudio de Kraft (2010) comprueba que tanto los usuarios como los no usuarios de Twitter poseen una marcada credibilidad en los tuits de los políticos. Si mutatis mutandis entendemos que los mensajes que se transmiten en el marco de los movimientos sociales por determinados actores son decodificados igualmente como mensajes con cierta intencionalidad, allí encontramos una variable que explica la razón de su alta probabilidad de influencia social.

Sobre este particular, la política (entendida como el interés por el bien común) involucra en la práctica un conjunto de actividades dependientes, en gran parte, del comportamiento de seres humanos, que no siempre son predecibles y que actúan muchas veces movidos por factores psicosociales que no necesariamente tienen raíces ideológicas definidas. Es este bien común (entendido en los términos de los objetivos concretos que se perciben y se persiguen) lo que moviliza a los individuos interconectados, quienes salen a las calles a protestar sin que previamente los hayan unido, en muchos casos, lazos de interacción efectiva en el mundo real.

Las representaciones sociales (tales como las imágenes y los recursos audiovisuales) son muy importantes para traducir el significado, los avatares y tendencias de la protesta, una visión simplificada de la ideología subyacente o la concepción de la realidad del movimiento. En este sentido, nos parece muy clara la apreciación de Doerr, Mattoni y Teune (2013: xi): “los movimientos sociales producen y evocan imágenes: ya sea como resultado de un esfuerzo planificado, explícito y estratégico, o accidentalmente, de una manera no pretendida ni deseada". Estimamos que la connotación de imagen expresada es multidimensional.

Harb (2013) enfatiza en la importancia del lenguaje en el marco de las protestas y la difusión de hechos que involucraron la denominada "Primavera árabe". Destaca que mientras el gobierno y sus voceros usaban el árabe estándar para dar a conocer su visión de la realidad e intentar mantener a toda costa el statu quo, el lenguaje de la protesta se acuñaba en cantos y expresiones habladas en árabe coloquial que era interpretado como el habla del pueblo ( $a s-s h a ' b)$ y alcanzaba, por ende, un mayor impacto en la población.

Nos parece pertinente aproximarnos al criterio de Fisher y Reuber (2011) quienes afirman que la utilización de medios sociales propicia nuevas modalidades de interacción social así como facilita igualmente las cogniciones y la conducta de quienes emplean estos recursos. En este sentido los elementos simbólicos que emplean los movimientos sociales resultarían fácilmente interiorizados y motivarían hacia la acción social. Hashtags, SMS 
o mensajes vía WhatsApp, a pesar de su aparente simplicidad tendrían un impacto importante en los usuarios.

En particular, el uso de los hashtags tiene considerable trascendencia; de ahí que la información sobre el propósito del movimiento social, a nuestro entender, debe darse a partir de la decisión del propio nombre del hashtag que se elija. Para Chang (2010), desde la teoría de la difusión de innovaciones, la posibilidad de adopción de los hashtags depende de la medida en que el usuario se ha expuesto a su información a través de Twitter como de alguna aplicación instalada en su teléfono móvil. Pero allí no queda la cosa: el empleo de los hashtags representa factor de importancia para la identidad del movimiento social aún en quienes no realizan una presencia activa en las acciones colectivas A este respecto, Dahlberg-Grundberg y Lindgren (2014) anotan que en tanto los seguidores de un movimiento usen los hashtags, se involucrarán en mayor medida, sin necesidad de estar presentes en los lugares de la protesta.

A decir de Harlow (2013), la narrativa de los medios sociales contribuye a la construcción de la identidad del movimiento social y promueve la acción colectiva. Ganz (2001) coincide con este criterio, asumiendo asimismo que la narrativa es central a los movimientos sociales en la medida en que incide en lo que sus integrantes desean lograr. Por su parte, Gerbaudo (2012) propone una interpretación fenomenológica acerca del rol movilizador de los medios sociales, enfatizando en el rol de las emociones en la construcción simbólica del imaginario colectivo y el sentido de pertenencia social de los activistas, a lo cual contribuye lo que denomina la "coreografía social" de los movimientos sociales contemporáneos.

\section{Narrativas y simbolismo para la acción colectiva}

En el caso de los movimientos sociales, la acción colectiva requiere información de base como marco de referencia, al igual que recursos motivacionales que hagan factible la persuasión de los potenciales adherentes. ¿Cómo se utilizan los elementos simbólicos en la actividad de los movimientos sociales?, ¿cuál es su impacto? Intentaremos responder a estas interrogantes a partir de la breve reseña de algunos movimientos sociales y de los recursos que emplearon.

El primero, particularmente significativo, sucedió en Egipto. La fotografía de Khaled Said era impactante: había sido tomada por sus propios familiares en la morgue donde reposaban sus restos con el rostro destrozado, tras la golpiza que le propinara la Policía. Fue subida a la red y se viralizó rápidamente. A partir de ello se creó el blog "Todos somos Khaled Said", el cual jugó un rol importante como motivador de la acción en la "Primavera árabe". Como indicador de su trascendencia, al 18 de enero de 2016, registraba 3784 130 "me gusta" en Facebook (https:/www.facebook.com/ElShaheeed). De acuerdo con Olesen (2013), el joven se convirtió en un "símbolo de la injusticia" y explica cómo se fue construyendo esta representación y sus interpretaciones relacionadas (figura 3 ). 
Figura 3: Difusión de la efigie de Khaled Said en redes sociales.

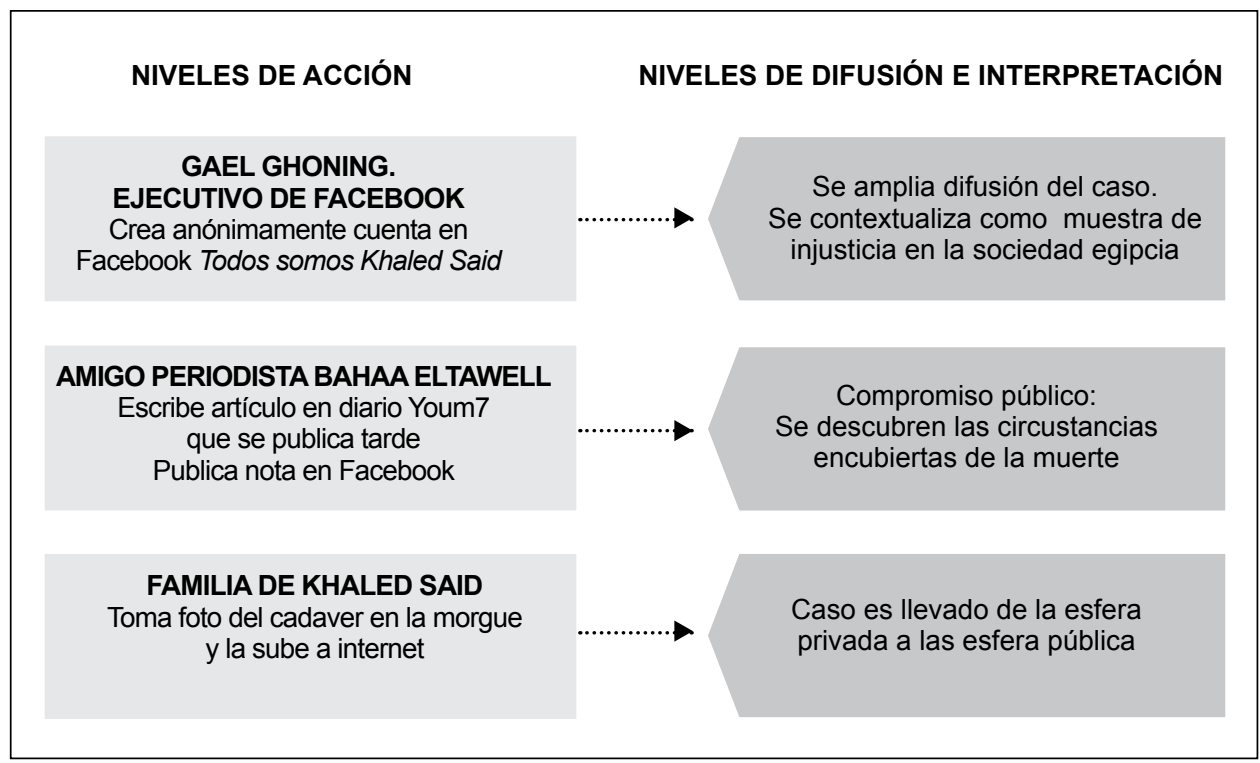

Fuente: Elaboración propia, basado en Olesen (2013).

El segundo caso ocurrió en nuestro país. El diario Perú21 (16/VII/2013) presentaba la transcripción de unos audios en los que se revelaba cómo se negociaba aparentemente en el Congreso de la República del Perú la elección de miembros del Tribunal Constitucional, del Banco Central de Reserva y del Defensor del Pueblo. La medida fue descalificada y categorizada como la "repartija" (peruanismo usado para referirse a acuerdos deshonestos que involucren reparto de beneficios).

Utilizando los hashtags \#tomemoslacalle, \#NoALaRepartija y \#VerguenzaNacional, así como un flashmob, miles de personas (especialmente jóvenes) se movilizaron y lograron que pocos días después el Congreso decidiera dejar sin efecto el acuerdo. La imagen de una lagartija fue uno de los recursos simbólicos empleados por los activistas, que se reprodujo reiteradamente en banderolas, camisetas y a través de las redes sociales. Poco después, el Congreso peruano se retractaría de su decisión.

Pese a las bajas temperaturas, más de cien mil estudiantes universitarios y escolares de Santiago de Chile marchaban por las calles de la ciudad (18/VIII/2011) protestando y cantando "Con lluvia y nieve el pueblo también se mueve" (Caballin, 2014). Los jóvenes protestaban contra los altos costos de la educación superior y los elevados créditos bancarios que debían pagar al finalizar sus estudios, demandando una educación pública gratuita y de calidad.

Las movilizaciones por cierto se habían iniciado en mayo. Facebook y Twitter fueron recursos importantes para congregar a los jóvenes en esta protesta. Una serie de hashtags 
habían promovido la movilización, invitando a unirse a la causa, así como a participar activamente: \#laalamedaesnuestra (aludiendo a la Alameda Bernardo O’Higgins, una de las principales vías del centro de la ciudad) y \#4deagosto (la fecha de inicio de las movilizaciones). Se logró un considerable impacto mediático a nivel internacional.

En 2013, el Primer Ministro turco Recep Tayyip Erdogan lanzó la propuesta de construcción de un centro comercial de estilo otomano en el Parque Gezi, situado en la Plaza Taksim de Estambul. El 28 de mayo de ese año estallaron las protestas de miles de manifestantes quienes ocuparon el parque. Luego de dos semanas fueron desalojados violentamente por la Policía. Entretanto, más de 3 millones y medio de personas habían participado en cerca de 5 mil demostraciones de protesta en diversos lugares de Turquía (De Bellaigue, 2013).

Onursoy (2015) realiza el análisis semiótico de uno de los posters (figura 4) que se crearon y compartieron en las plataformas virtuales durante estas protestas a través de las redes sociales. El poster estudiado es, a su vez, parte de la foto de portada de la comunidad Diren Gezi Parki en Facebook (https://www.facebook.com/occupygezipark/).

Figura 4: Poster Diren Gize Parki.

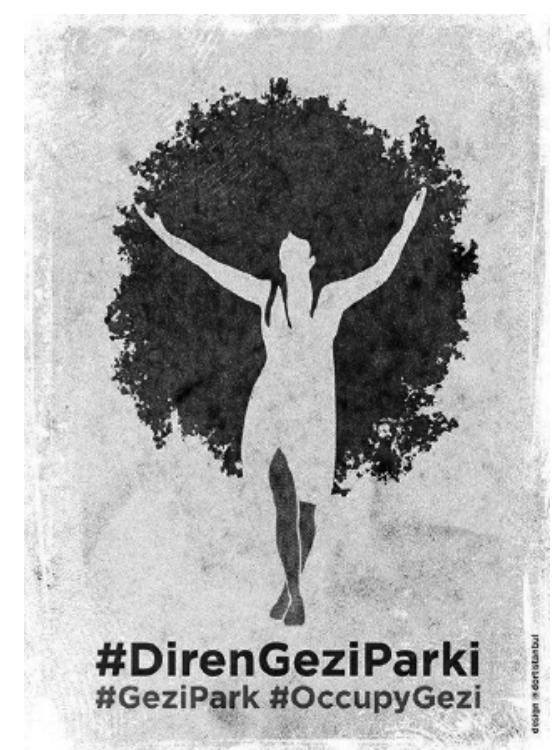

Fuente: Diren Gezi Parki (cuenta oficial en Facebook, 2015).

El predominio del verde, que implica naturaleza y esperanza (color del Islam), la silueta de la mujer formando un conjunto con el árbol (donde las hojas son el pelo de la mujer y sus piernas, de color marrón, el tronco del árbol) lo cual refuerza la idea de la unión del ser humano con la naturaleza. La postura de la mujer con los brazos extendidos y las manos hacia arriba y un pie avanzando representan el poder de hacer. El hashtag \#Diren Gize Parki ("Resiste Gize Park") motiva a la acción social. 


\section{Reflexiones finales}

Sobre las redes sociales se han publicado miles de artículos y un sinnúmero de libros. Eventualmente, sin necesidad de ser tecnofílico, podría sobredimensionarse su rol en el caso de los movimientos sociales, los cuales no se producen en caso alguno por el mero empleo de los recursos tecnológicos ni tampoco surgen espontáneamente.

Dado que no lo habíamos explicitado previamente creemos pertinente afirmar que concordamos en términos generales con el criterio de Gerbaudo (2012) referido a los diferentes roles que desempeñan las redes en los movimientos sociales. De este modo, en pocas palabras, Twitter y Facebook actúan como catalizadores de las movilizaciones, mientras que Flickr, Instagram y YouTube proporcionan testimonios en constante actualización sobre el curso que van tomando los acontecimientos. Indudablemente, han contribuido a este propósito los avances tecnológicos de los teléfonos móviles, con acceso a la Internet y a las redes sociales, amén de su plurifuncionalidad.

Es evidente igualmente que las modalidades de uso de la narrativa y, en general, de los recursos simbólicos no han sido idénticas en todos los casos, pues ello ha dependido de factores contextuales, culturales y coyunturales. No obstante a partir del 2007 se empezó a utilizar el hashtag (\#) para etiquetar los mensajes y lograr que se conviertan en tendencia, lo que (en términos de las redes sociales) equivale a su popularización, lo cual coincide con las expectativas de quienes promueven los movimientos sociales.

Al reflexionar sobre lo escrito, quisiéramos anotar igualmente que no necesariamente todos los movimientos sociales han sido exitosos, pues ello podría deducirse erróneamente de la frecuente alusión a la "Primavera árabe". Es evidente, por ejemplo, que la denominada "Revolución del Azafrán” en Myanmar fracasó, que la represión fue sangrienta, así como que cientos de activistas y monjes budistas fueron encarcelados.

El análisis de los movimientos sociales en los cuales se hace uso de los medios sociales se enmarcaría temporalmente en lo que autores como Wolikow (1998) y Fazio (1998) denominan "historia del tiempo presente". Sin dejar de considerar las reservas que plantea Scannel (2014), sobre el estudio actual de la influencia duradera de Facebook y Twitter, hemos insistido a lo largo de nuestro trabajo en el aporte que proporciona la evidencia científica más reciente sobre el importante papel de las redes sociales en los movimientos sociales contemporáneos. El presente trabajo ha pasado revista a un número limitado de casos así como de investigaciones. Estimamos, por ello, que constituye un ejercicio de aproximación preliminar a una problemática bastante más amplia que valdría la pena abordar posteriormente.

\section{Fuentes consultadas}

Caballin, C. (2014). "Estudiantes conectados y movilizados: El uso de Facebook en las protestas estudiantiles en Chile". Comunicar XXII, núm. 43, pp.25-33. 
Candón, J. (2011). Internet en movimiento: Nuevos movimientos sociales y nuevos medios en la sociedad de la información [tesis doctoral]. Madrid: Universidad Complutense de Madrid, Facultad de Ciencias de la Información. Extraída el 10/VIII/2016 desde http://eprints.ucm.es/12085/1/T32702.pdf

Chang, H. (2010). “A New Perspective on Twitter Hashtag Use: Diffusion of Innovation Theory Paper presented at the 2010 Annual Meeting, Association for Information Science and Technology”. Pennsylvania, Estados Unidos. Extraída el 29/III/2016 desde https://www.asis.org/asist2010/proceedings/proceedings/ASIST_AM10/ submissions/295_Final_Submission.pdf

Conover, M.; Davis, C.; Ferrara, E.; McKelvey, K.; Menczer F. y Flammini, A. (2013). "The Geospatial Characteristics of a Social Movement Communication Network". PLoS ONE, vol. 8, núm. 3. Extraída el 23/I/2016 desde

http://journals.plos.org/plosone/article?id=10.1371/journal.pone.0055957

Conover, M.; Ferrara, E.; Menczer, F. y Flammini, A. (2013). "The Digital Evolution of Occupy Wall Street”. PLoS ONE, vol. 8, núm. 5. Extraída el 29/X/2015 desde http://journals.plos.org/plosone/article?id=10.1371/journal.pone.0064679

Dahlberg-Grundberg, M. y Lindgren, S. (2014). "Translocal Frame Extensions in a Networked Protest: situating the \#IdleNoMore hashtag". IC - Revista Cientifica de Información y Comunicación, núm. 11, pp. 49-77.

De Bellaigue, C. (2013, diciembre 19). "Turkey: 'Surreal, Menacing... Pompous"”. Extraída el 12/V/2016 desde http://www.nybooks.com/articles/2013/12/19/turkey-surrealmenacing-pompous/?pagination=false

Della Porta, D. y Diani, M. (2006). Social Movements: An Introduction. Oxford: Blackwell.

Doerr, N.; Mattoni, A. y Teune, S. (2013). "Toward a visual analysis of social movements, social conflict and political mobilization”, pp. xi-xxvi. En Doerr, N.; Mattoni, A. y Teune, S. (eds.). Advances in the Visual Analysis of social movements. Yorkshire: Emerald Books.

Fazio, H. (1998). "La historia del tiempo presente: una historia en construcción”. Historia Crítica, núm. 17, pp. 47-57. Extraída el 11/VIII/2016 desde

https://historiacritica.uniandes.edu.co/datos/pdf/descargar.php?f=./data/H Critica_17/05_H_Critica_17.pdf

Fischer, E. y Reuber, R. (2011). "Social interaction via new social media: (How) can interactions on Twitter affect effectual thinking and behavior?". Journal of Business Venturing, núm. 26, pp. 1-18.

Ganz, M. (2001). “The Power of Story in Social Movements”. Extraída el 10/VIII/2016 desde http://leadingchangenetwork.org/wp-content/uploads/2012/05/Power_of_Story-inSocial-Movements.pdf 
Gerbaudo, P. (2012). Tweets and the streets: Social media and contemporary activism. Londres: Pluto Press.

Harb, N. (2013). "Irhal! The role of language in the Arab spring" [tesis de maestría]. Washington DC: Georgetown University, Graduate School of Arts and Sciences.

Harlow, S. (2013). 'It was a 'Facebook revolution': Exploring the meme-like spread of narratives during the Egyptian protests”. Revista de Comunicación, núm. 12, pp. 59-82.

Ibarra, P. (2000). "Los estudios sobre los movimientos sociales: estado de la cuestión". Revista Española de Ciencia Política. Vol. 1, núm. 2, pp. 271-290.

Iosifidis, A.; Tsapanos, N. y Pitas, I. (2016). "Graphs in Social and Digital Media". En Pitas, I. (ed.). Graph-based social media analysis. Florida: CRC Press.

Jègues-Wolkiewiez, C. (2012). Sur les chemins étoilés de Lascaux. París: Éditions La Pierre Philosophale.

Kraft, R. (2010). A Twitter Revolution? Uses \& Gratifications and Credibility of Twitter [tesis de maestría]. Austin: The University of Texas, Faculty of the Graduate School.

Markham, A. y Lindgren, S. (2014). "From Object to Flow: Network Sensibility, Symbolic Interactionism, and Social Media”. Studies in Symbolic Interaction, núm. 43, pp. 7-41.

Martínez Romero, U. (2012). Movimientos sociales y la autocomunicación de masas: Una revisión del movimiento 12-M [tesis de licenciatura]. San Luis Potosí, México: El Colegio de San Luis. Extraída el 11/VIII/2016 desde http://biblio.colsan.edu.mx/tesis/MartinezRomeroUlisesPavel.pdf

Mathieu, L. (2004). Comment lutter? Sociologie et mouvements sociaux. París: Les éditions Textuel.

Maxwell, G.; Oliver, P. y Prahl, R. (1988). "Social Networks and Collective Action: A Theory of the Critical Mass". American Journal of Sociology. Vol. 94, núm. 3, pp. 502-534.

Olesen, T. (2013). "“We are all Khaled Said' Visual injustice symbols in the Egyptian Revolution 2010-2011”, pp. 3-25. En Doerr, N.; Mattoni, A. y Teune, S. (eds.). Advances in the Visual Analysis of social movements. Yorkshire: Emerald Books.

Onursoy, S. (2015). "A Semiotic Analysis of an Activist Image in Social Media Online Journal of Art and Design”. Vol. 3, núm. 2. Extraída el 11/VIII/2016 desde http://ojad.emu.edu.tr/articles/32/321.pdf

Perú21 (2013, julio 16). “Audios confirman que hubo 'repartija' en el Congreso". Extraída el 10/VI/2014 desde

http://peru21.pe/politica/audio-confirma-que-hubo-repartija-congreso-2140482 
Protzel, J. (2016, agosto 2). Comunicación por correo electrónico. Lima.

Scannel, P. (2014). "La historia, los medios y la comunicación”, pp. 346-371. En Jensen, K. (ed.). La comunicación y los medios. Metodología de la investigación cualitativa y cuantitativa. México D. F.: Fondo de Cultura Económica.

Silva, J. (2010). Discurso, representación y cultura: La valoración simbólica de los noticiarios de televisión. Los movimientos sociales chilenos y la visibilidad social [tesis doctoral]. Valladolid: Universidad de Valladolid.

Susen, S. (2010). "Los movimientos sociales en las sociedades complejas", pp. 149-226. En Basconzuelo, C.; Morel, T. y Susen, S. (eds.). Ciudadanía territorial y movimientos sociales. Historia y nuevas problemáticas en el escenario latinoamericano y mundial. Río Cuarto, Argentina: Ediciones del ICALA.

Tarrow, S. (2012). El poder en movimiento: loa movimientos sociales, la acción colectiva y la política. Madrid: Alianza Editorial.

Taştan, C. (2013). "The Gezi Park Protests in Turkey: A Qualitative Field Research". Insight Turkey. Vol. 15, núm. 3, pp. 27-38. Extraída el 11/VIII/2016 desde http://file.insightturkey.com/Files/Pdf/15_03_2013_tastan.pdf

Tilly, C. (2004). Social movements 1768-2004. Colorado: Paradigm Publishers.

Villafuerte, L. (2007). "Movimientos sociales: De la Psicología Social a las identidades sociales - Una revisión teórica”. Revista de Ciencias Humanas, núm. 36, pp. 157-179.

Wolikow, S. (1998). "L' histoire du temps présent en question", pp. 9-24. En Oú est la histoire du temps présent? Actes du colloque transfrontalier. Universidad de Borgoña, Francia. Extraída el 12/VIII/2016 desde http://tristan.u-bourgogne.fr/CGC/publications/ouenesthistoiretemps/ ouenhistoiretempspresent.pdf 